\title{
Research Paper: Arrestees Substance Abuse: Moving Toward Rehabilitation Camps or Prisons
}

\author{
Fahimeh Mohseni $^{1}$ (D), Elie Moghimi Khorasani² (D), Ali Asghar Nadi Ghara ${ }^{3}$ (D) Raheleh Rafaiee $^{4^{*}}$ (D) \\ 1. Student Research Committee, School of Medicine, Shahroud University of Medical Sciences, Shahroud, Iran. \\ 2. Department of Administration, Faculty of Management, Payamnoor University, Shahroud, Iran. \\ 3. Health Sciences Research Center, Addiction Research Institute, Mazandaran University of Medical Sciences, Sari, Iran. \\ 4. Department of Neuroscience, School of Advanced Technologies in Medicine, Mazandaran University of Medical Sciences, Sari, Iran.
}

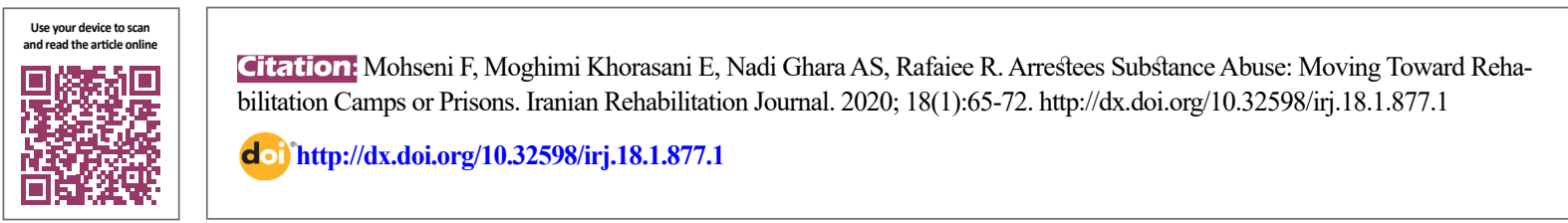

\section{(i) (s)}

Article info:

Received: 27 Mar 2019

Accepted: 10 Oct 2019

Available Online: 01 Mar 2020

\section{Keywords:}

Addiction, Drug abuse, Arrest, Rehabilitation camp, Prison

\section{A B S T RACT}

Objectives: Illicit drug abuse and drug-related crimes are still a growing problem worldwide. Understanding the increasing number of individuals arrested for drug charges, as well as their characteristics is necessary to predict and establish preventive and treatment programs.

Methods: This cross-sectional study was conducted in Shahroud, Northeast of Iran from 20152018. Data were collected at the time of arrest from all homeless addicts and drug offenders arrested by the police and were sent to the rehabilitation camps or prisons $(n=5486)$.

Results: Drug-related charges were the largest category of arrest charges in Shahroud. The mean age of arrestees had significantly decreased each year. In total, $19.1 \%$ of the arrestees were referred to the rehabilitation camps ( $18.6 \%$ male and $40.3 \%$ female). The number of cases arrested for drug charges referred to the rehabilitation camps had significantly increased over time in both men and women. The number of arrestees showed an increase each year, whereas their mean age had decreased significantly.

Discussion: Drug-related laws in Iran have been reformed, emphasizing the judicial supervision of arrest, treatment, and release processes. Treatment of arrestees with drug abuse provides opportunities for decreasing substance abuse and criminal behaviors and rearrests. 


\section{Highlights}

- Drug-related charges were the largest category of arrest charges.

- Arrestees with drug abuse were predominantly young males, often single, with a low level of education.

- The mean age of arrestees with drug abuse significantly decreased every year.

- The number of arrestees with drug abuse who referred to the rehabilitation camps significantly increased.

\section{Plain Language Summary}

In small cities of Iran, which are situated on trafficking routes, drug addiction and trafficking are prevalent among young people. Drug charges comprised the largest category of arrest charges in Shahroud, Iran. Regarding the high cost and negative effects of imprisoning the substance users, many authorities have begun to consider different alternatives approaches. The number of arrestees with drug abuse referring to the rehabilitation camps significantly increased over time in both men and women. It should be noted that those who were referred to compulsory camps by the police are treated free of charge. Individual, family, and group counseling is included in the considered intervention in camps to prevent relapse after recovery and achieve complete abstinence.

\section{Introduction}

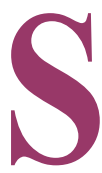

ubstance abuse and drug-related crimes threaten public health and social security. Drug abusers and smugglers are more likely to commit crimes compared with others. Addicts normally show criminal and violent behaviors to gain access to illegal drugs. Many illegal activities have arisen from drugs [1]. Drug offenders comprise $3-29 \%$ of the prisoners in the European Union (EU), $4-29 \%$ of the prisoners in non-EU European countries, $5-53 \%$ of the prisoners in the United States., and $10-58 \%$ of the prisoners in Asia and Oceania [2]. In the United States, $82 \%$ of drug-related arrests were due to drug possession charges in 2009 [3]. In Iran, at least, $50 \%$ of all prisoners are imprisoned because of drug-related offenses, and as many as $70 \%$ use illicit drugs [4]. Generally, the number of drug-related prisoners is high in Iran, and more than 10000 drug traffickers were executed in the last decade [5]. Also, about 80000 people are imprisoned for drug-related offenses [6].

In an attempt to reduce crimes in the community, intervention programs for drug users have been integrated into the criminal justice system to be carried out at the time of arrest, prison sentence, and imprisonment and while receiving community services. Reduced criminal activity has been also reported among drug users receiving treatment for addiction [7]. The Arrestee Drug Abuse Monitoring (ADAM), originally established in 1987 by the National Institute of Justice, was a survey conducted by the United States to gauge the prevalence of illegal drug use among arrestees and monitor druguse trends, treatment needs, and risky behaviors among recently booked arrestees in more than 20 large cities of the United States [8].

ADAM survey in 1999 revealed that cocaine was used by nearly one-third of all adult arrestees, while opiate was not that much popular among adult arrestees, with about $7-8 \%$ positive results for these drugs via urinalysis. Between 1991 and 2000, drug abuse arrests increased by $48 \%$ in males and $59 \%$ in females [9]. The ADAM data in 2002-2008 revealed that the prevalence of selfreported marijuana use was $42.4 \%$ among adult male arrestees over the past month. In addition, the prevalence of rock cocaine, crack, methamphetamine, and heroin use was $20.1 \%, 12.9 \%, 11.5 \%$, and $11.5 \%$, respectively [10]. Conversely, ADAM data in 2000-2010 clearly indicated that the crack epidemic had declined among male arrestees who tended to serve their sentences. Based on the finding, the drug of choice among younger arrestees continues to be marijuana, which is associated with fewer drug-related problems than crack cocaine [11, 12].

The results of a conducted in London, UK, showed that approximately half of arrestees reported heroin (55\%) and crack cocaine (49\%) use, $51 \%$ of whom had received no previous treatment for addiction and the majority of these prisoners $(80 \%)$ reported previous convictions [13]. Globally, more than two-thirds of all countries have legislation for mandatory drug treatment [14]. In Iran, 
the Police, besides fighting against drug-related crimes, is also involved in providing mandatory treatment programs for addictions [15]. For this purpose, homeless addicts are arrested and sent to rehabilitation camps by the Iranian Anti-Narcotics Force [16]. However, considering the specific Iranian culture and society, which provides a protective factor against substance abuse, only a few studies have been carried out on the background of drug arrestees and their drug-use behaviors in Iran.

To find an effective treatment for drug abuse in arrestees and promote suitable programs and strategies for reducing substance use in criminal justice groups, it is important to report detailed information on drug abuse charges, drug abuse patterns, and treatment demands among high-risk populations, such as arrestees. The current study aimed at investigating an increase in the number of drug-related arrests and the arrestees' transfer to rehabilitation camps or prisons to provide the necessary information for better planning against substance abuse.

\section{Methods}

In this retrospective, cross-sectional study, data were collected from adult addicts ( $>18$ years) and drug offenders arrested by the police force in Shahroud, a small city in Northeast of Iran. Following the arrests, some demographic variables, such as age, gender, educational level, occupational status, and type of drug abuse were obtained and recorded by the police force within the first hour of being booked into local jails. Drugs were divided into three groups: natural (opium, burned opium, and opium sap), synthetic (crystal meth), and semi-synthetic (heroin and Iranian crack).

The arrestees were sent to the court and referred to a judge. According to the investigations and collected evidence, when the arrested person was only a substance abuser and had not committed any other crimes, the judge will refer him/her to a rehabilitation camp (compulsory) as a residential rehabilitation center for addiction treatment. Only arrestees who had committed crimes were imprisoned. In this study, the subjects were selected using census sampling method. Information was collected from those arrested due to drug-related crimes through a four-year period from 2015-2018. Data were collected using checklists and analyzed through the Minitab 18 and Microsoft Excel.

\section{Results}

Table 1 presents the census report of the sociodemographic characteristics of drug offenders arrested by the police force in Shahroud. The number of arrestees was 846 in 2015, 1212 in 2016, 1447 in 2017, and 1981 in 2018. In total, 5437 cases $(97.3 \%)$ were male and 139 cases $(2.7 \%)$ were female. The mean age of the arrestees was 31.44 years $(\mathrm{SD}=10.27)$, ranged $18-67$ years. The age of arrestees with drug abuse significantly had decreased every year from 2015-2017 $(\mathrm{P}<0.05)$, except for 2017-2018. The mean age of subjects at the onset of drug abuse was 19.9 years. Also, $33.9 \%$ of them had been imprisoned at least once.

Opium was the most commonly abused drug among the arrestees. Table 2 presents the types of consumed drugs in the arrestees. About $6.7 \%$ of the subjects had abused drugs intravenously. The findings showed that $56.8 \%$ of the arrestees had a family history of drug abuse. Overall, $40 \%$ of male and $18 \%$ of female arrestees had been sent to rehabilitation camps for four years. Table 3 shows the census report of individuals arrested for drug charges who were referred to rehabilitation camps or prisons. By 2018, the number of female arrestees had decreased significantly in comparison with male arrestees $(\mathrm{P}<0.0001)$. Additionally, the number of cases arrested for drug charges referred to the rehabilitation camps had significantly increased over time in both men and women.

\section{Discussion}

In this study, we evaluated the demographic characteristics, drug abuse patterns, and the number of arrestees sent to the rehabilitation camps in Shahroud, Iran. The arrestees were predominantly young males, often single, with a low level of education. Women comprised a small number of subjects and also no prison-based drug treatment facilities have been considered for this population.

The age range of the arrestees with drug-related crimes was 30-33 years. Considering the demographic characteristics of the arrestees, our participants were as young as the samples studied in other relevant studies, such as in French [17, 18], American [19], Chinese [20], and English [21] arrestees. Generally, being young and unemployed can increase the risk of being arrested [22]. In the studied subjects, those with non-governmental jobs and no access to higher education were more than unemployed cases. One possible explanation is that most of the arrestees had temporary jobs; therefore, they purchased and sold illegal drugs because of their low income.

Although smuggling, producing, and distributing drugs are serious offenses in Iran, associated with long-term imprisonment and serious penalties, drug-related crimes continue to be a growing problem. Our results showed 
Table 1. Sociodemographic characteristics of the arrestees

\begin{tabular}{|c|c|c|c|c|c|}
\hline \multirow{2}{*}{\multicolumn{2}{|c|}{ Variable }} & \multicolumn{4}{|c|}{ Mean $\pm S D$} \\
\hline & & 2015 & 2016 & 2017 & 2018 \\
\hline \multicolumn{2}{|c|}{ Age } & $33.59 \pm 10.9 *$ & $31.56 \pm 9.1^{*}$ & $30.1 \pm 8.8^{*}$ & $30.52 \pm 12.3$ \\
\hline \multirow{2}{*}{\multicolumn{2}{|c|}{ Variables }} & \multicolumn{4}{|c|}{ No. (\%) } \\
\hline & & 2015 & 2016 & 2017 & 2018 \\
\hline \multirow{2}{*}{ Gender } & Male & $812(96)$ & 1186 (97.9) & $1408(97.3)$ & $1941(98)$ \\
\hline & Female & $35(4)$ & $26(2.1)$ & $39(2.7)$ & $40(2)$ \\
\hline \multirow{3}{*}{ Marital status } & Married & $322(38.1)$ & 478 (39.5) & $568(39.3)$ & 788 (39.8) \\
\hline & Single & $457(54.1)$ & $614(50.7)$ & 727 (50.3) & $1022(51.6)$ \\
\hline & Others & $67(7.8)$ & $720(9.8)$ & $152(10.4)$ & $171(8.6)$ \\
\hline \multirow{5}{*}{ Educational level } & Illiterate & $42(5)$ & $60(5)$ & $86(6)$ & $59(3)$ \\
\hline & Primary school & $219(26)$ & $303(25)$ & $405(28)$ & $435(22)$ \\
\hline & Secondary school & $321(38)$ & $424(35)$ & $448(31)$ & $614(31)$ \\
\hline & High school and diploma & $211(25)$ & $351(29)$ & $405(28)$ & $792(40)$ \\
\hline & College and more & $53(6)$ & $74(6)$ & $103(7)$ & $81(4)$ \\
\hline \multirow{4}{*}{ Employment status } & Unemployed & $60(7)$ & $49(4)$ & $44(3)$ & $99(5)$ \\
\hline & Governmental jobs & $9(1)$ & $18(1.5)$ & $22(1.5)$ & $20(1)$ \\
\hline & Non-government jobs & $466(55)$ & 715 (59) & 854 (59) & $1545(78)$ \\
\hline & Others & 311 (37) & $430(35.5)$ & $527(36.5)$ & 317 (16) \\
\hline
\end{tabular}

*The age of the arrestees significantly decreased $(\mathrm{P}<0.05)$.

Пranian Rehabilitation \ournal

Table 2. Type of drug consumed by arrestees

\begin{tabular}{cccccc}
\hline Type of Drug No. (\%) & $\mathbf{2 0 1 5}$ & $\mathbf{2 0 1 6}$ & $\mathbf{2 0 1 7}$ & $\mathbf{2 0 1 8}$ & $\mathbf{F}^{*}$ \\
\hline Natural & $617(73)$ & $921(76)$ & $1056(73)$ & $1465(74)$ & \\
Synthetic & $161(19)$ & $193(16)$ & $260(18)$ & $277(14)$ & 0.025 \\
Semi-synthetic & $68(8)$ & $98(8)$ & $131(9)$ & $239(12)$ & \\
\hline
\end{tabular}

Пranian Rehabilitation \ournal

* Consuming natural drugs is significantly higher than synthetic and semisynthetic drugs, but the pattern.

Table 3. The census report of drug offenders arrested in Shahroud moved to camps or prisons

\begin{tabular}{|c|c|c|c|c|c|c|c|c|c|}
\hline \multirow{2}{*}{$\begin{array}{c}\text { Year } \\
\text { No. (\%) }\end{array}$} & \multicolumn{2}{|c|}{2015} & \multicolumn{2}{|c|}{2016} & \multicolumn{2}{|c|}{2017} & \multicolumn{2}{|c|}{2018} & \multirow{2}{*}{$\mathrm{F}^{*}$} \\
\hline & Camp & Prison & Camp & Prison & Camp & Prison & Camp & Prison & \\
\hline Men & $67(8.25)$ & 745 (91.75) & $\begin{array}{c}213 \\
(17.95)\end{array}$ & $\begin{array}{c}973 \\
(82.04)\end{array}$ & $348(24.71)$ & $\begin{array}{c}1060 \\
(75.28)\end{array}$ & $365(18.80)$ & $\begin{array}{c}1576 \\
(81.19)\end{array}$ & 0.001 \\
\hline Women & $7(20.5)$ & 27 (79.41) & $8(30.76)$ & $18(69.24)$ & 19 (48.71) & 20 (51.28) & $22(55)$ & $18(45)$ & 0.001 \\
\hline Total & $74(8.75)$ & 772 (91.25) & $\begin{array}{c}221 \\
(18.23)\end{array}$ & $\begin{array}{c}991 \\
(81.76)\end{array}$ & $367(25.36)$ & $\begin{array}{c}1080 \\
(74.63)\end{array}$ & 387 (19.53) & $\begin{array}{c}1594 \\
(80.46)\end{array}$ & 0.001 \\
\hline
\end{tabular}

Пranian Rehabilitation Dournal

*The number of arrestees referred to the rehabilitation camps significantly increased over time in men and women.

an increase in drug abuse rate among arrestees in Shahroud. Opiates, marijuana, alcohol, and psychostimulants are the drugs of choice among arrestees [23, 24].
Self-reporting a relatively soft drug, such as marijuana by younger arrestees is more than a relatively hard drug, like psychostimulants [25]. In this regard, Hunt et al. (2015) reported that a substantial proportion of arrestees require 
treatment for both mental and substance use disorders. However, relatively few arrestees had received these services over the past year or throughout their lifetime [14].

Currently, compulsory rehabilitation is a major drug rehabilitation intervention in some countries [26]. In our study, the number of drug-related arrestees, who were referred to the rehabilitation camps showed an increase each year. However, according to the results of studies in Southeast Asian countries, the total number of people in compulsory detention centers decreased by only 4\% between 2012 and 2014 [27]. On the other hand, previous reports have revealed forced labor, physical abuse, and even sexual abuse in these camps [28]. Nine Asian countries, such as Cambodia, China, Indonesia, Laos, Malaysia, Myanmar, Philippines, Thailand, and Vietnam have committed to transition from compulsory detention treatment models towards voluntary community-based treatment services, based on expanded voluntary community-based drug dependence care in health centers [29].

Few countries offer opioid agonist therapy in detention centers, except for Iran, where methadone therapy is provided in compulsory treatment centers $[30,31]$. Arrestees sent by the police to compulsory camps are treated free of charge in Iran [15], however, policymakers have established a cohesive program to prevent relapse and re-entry into the addiction cycle after discharge. Individual, family, and group counseling is also an important part of camp services for the prevention of relapse after recovery and achieving complete abstinence.

A twelve-step intervention program is another useful strategy used by the government and rehabilitation camps to prevent relapse after recovery and achieve complete abstinence. Subcommittee meetings of the Narcotics Anonymous (NA) and Alcoholic Anonymous (AA) associations, as non-governmental organizations, are held in prisons and camps. The purpose of these meetings is to transfer the message of recovery to addicts whose attendance in regular meetings is restricted [32-34]. Moreover, arrestees can use facilities to build a business after discharge from rehabilitation camps.

\section{Conclusion}

Regarding the high cost and negative effects of imprisoning the substance users, many authorities have directed their attention to different alternative approaches. Drug-related laws in Iran have been reformed, emphasizing the judicial supervision of arrest, treatment, and release processes. When drug addicts and offenders are arrested, those with only addiction problems with no other criminal charges are referred by the judge to rehabilitation camps for drug abuse treatment. The obtained findings showed that the number of cases arrested for drug charges referred to the rehabilitation camps had significantly increased over time in both men and women. Treatment of arrestees with drug abuse provides an opportunity to decrease substance abuse and the associated criminal behaviors and rearrests.

\section{Ethical Considerations}

\section{Compliance with ethical guidelines}

The local Ethics Committee affiliated with the Shahroud University of Medical Sciences approved this study (Code: IR.SHMU.REC.1398.144). The present study complies with contemporary laws and regulations in Iran.

\section{Funding}

This research did not receive any specific grant from funding agencies in the public, commercial, or not-forprofit sectors.

\section{Authors' contributions}

Conceptualization, methodology, original draft preparation: Fahimeh Mohseni; Data curation, investigation: Elie Moghimi Khorasani; Formal analysis: Ali Asghar Nadi Ghara; Supervision, writing - review \& editing: Raheleh Rafaiee.

\section{Conflict of interest}

The authors declared no conflict of interest.

\section{Acknowledgments}

The authors offer grateful acknowledgements to Shahroud University of Medical Sciences and the Police of Shahroud for their cooperation.

\section{References}

[1] Rafaiee R, Olyaee S, Sargolzaiee A. The relationship between the type of crime and drugs in addicted prisoners in Zahedan central prison. International Journal of High Risk Behaviors \& Addiction. 2013; 2(3):139-40. [DOI:10.5812/ijhrba.13977] [PMID] [PMCID]

[2] Lattimore PK, Steffey DM, Gfroerer J, Bose J, Pemberton MR, Penne MA. Arrestee substance use: Comparison of es- 
timates from the national survey on drug use and health and the arrestee drug abuse monitoring program. CBHSQ Data Review: Substance Abuse and Mental Health Services Administration (US); 2012. [PMID]

[3] Nikpour G. Drugs and drug policy in the Islamic Republic of Iran. Middle East Brief. 2018; 119:1-8.

[4] Calabrese J. Iran's war on drugs: Holding the line. The Middle East Institute, Policy Brief. 2007; 3:1-18.

[5] Aliverdinia A, Pridemore WA. An overview of the illicit narcotics problem in the Islamic Republic of Iran. European Journal of Crime Criminal Law and Criminal Justice. 2008; 16(2):155-70. [DOI:10.1163/157181708X308434]

[6] Peters RH, Murrin MR. Effectiveness of treatment-based drug courts in reducing criminal recidivism. Criminal Justice and Behavior. 2000; 27(1):72-96. [DOI:10.1177/0093854800027001005]

[7] Katz CM, Webb VJ, Decker SH. Using the Arrestee Drug Abuse Monitoring (ADAM) program to further understand the relationship between drug use and gang membership. Justice Quarterly. 2005; 22(1):58-88. [DOI:10.1080/0741882042000333645]

[8] Bennett T, Holloway K, Williams T, Britain G. Drug use and offending: Summary results from the first year of the NEWADAM research programme. London: Home Office; 2001.

[9] Lattimore PK, Steffey DM, Gfroerer J, Bose J, Pemberton MR, Penne MA. Arrestee substance use: Comparison of estimates from the national survey on drug use and health and the arrestee drug abuse monitoring program. US: Substance Abuse and Mental Health Services Administration; 2014. [PMID]

[10] Golub A, Brownstein HH. Drug generations in the 2000s: An analysis of arrestee data. Journal of Drug Issues. 2013; 43(3). [DOI:10.1177/0022042613475599] [PMID] [PMCID]

[11] Kilmer B, Everingham S, Caulkins J, Midgette G, Pacula R, Reuter $\mathrm{P}$, et al. What America's users spend on illegal drugs, 2000-2010: Santa Monica, CA: RAND corporation, 2014. [DOI:10.7249/RR534]

[12] Oerton J, Hunter G, Hickman M, Morgan D, Turnbull P, Kothari $G$, et al. Arrest referral in London police stations: Characteristics of the first year. A key point of intervention for drug users? Drugs: Education, Prevention and Policy. 2003; 10(1):73-85. [DOI:10.1080/0968763021000040914]

[13] Israelsson M, Israelsson M, Gerdner A. Compulsory commitment to care of substance misusers: International trends during 25 years. European Addiction Research. 2012; 18(6):302-21. [DOI:10.1159/000341716] [PMID]

[14] Ghiabi M. Maintaining disorder: The micropolitics of drugs policy in Iran. Third World Quarterly. 2018; 39(2):277-97. [DO I:10.1080/01436597.2017.1350818] [PMID] [PMCID]

[15] Ghiabi M. Under the bridge in Tehran: Addiction, poverty and capital. Ethnography. 2018: 1-25. [DOI:10.1177/1466138118787534]

[16] Verdier E, Denis C, Bourokba N, Chauvin P, Chariot P. Social vulnerabilities and health conditions of arrestees in the Greater Paris area, France, in 2013: A multicentre crosssectional study. International Journal of Legal Medicine. 2018; 132(3):897-905. [DOI:10.1007/s00414-017-1727-y] [PMID]
[17] Vincent R, Beaufrère A, Chariot P. Detainees arrested for the first time in French police stations. Journal of Forensic and Legal Medicine. 2015; 31:1-6. [DOI:10.1016/j.jflm.2014.12.017] [PMID]

[18] Cheon H, Decker SH, Katz CM. Medical marijuana and crime: Substance use and criminal behaviors in a sample of arrestees. Journal of Drug Issues. 2018; 48(2):182-204. [DOI:10.1177/0022042617743775]

[19] Edlund L, Li H, Yi J, Zhang J. Sex ratios and crime: Evidence from China. Review of Economics and Statistics. 2013; 95(5):1520-34. [DOI:10.1162/REST_a_00356]

[20] Patton D. An exploration of the external validity of self-report amongst arrestees. Surveillance \& Society. 2004; 2(4):56480. [DOI:10.24908/ss.v2i4.3364]

[21] Janko Z, Popli G. Examining the link between crime and unemployment: A time-series analysis for Canada. Applied Economics. 2015; 47(37):4007-19. [DOI:10.1080/00036846.201 5.1023942]

[22] Belenko S, Hiller M, Hamilton L. Treating substance use disorders in the criminal justice system. Current Psychiatry Reports. 2013; 15(11):414. [DOI:10.1007/s11920-013-0414-z] [PMID] [PMCID]

[23] Taxman FS, Perdoni ML, Harrison LD. Drug treatment services for adult offenders: The state of the state. Journal of Substance Abuse Treatment. 2007; 32(3):239-54. [DOI:10.1016/j. jsat.2006.12.019] [PMID] [PMCID]

[24] Webb VJ, Katz CM, Decker SH. Assessing the validity of self-reports by gang members: Results from the Arrestee Drug Abuse Monitoring Program. Crime \& Delinquency. 2006; 52(2):232-52. [DOI:10.1177/0011128705277972]

[25] Kamarulzaman A, McBrayer JL. Compulsory drug detention centers in East and Southeast Asia. International Journal of Drug Policy. 2015; 26(Suppl. 1):S33-7. [DOI:10.1016/j.drugpo.2014.11.011] [PMID]

[26] Lunze K, Lermet O, Andreeva V, Hariga F. Compulsory treatment of drug use in Southeast Asian countries. The International Journal on Drug Policy. 2018; 59:10-15. [DOI:10.1016/j.drugpo.2018.06.009] [PMID]

[27] Amon J, Pearshouse R, Cohen J, Schleifer R. Compulsory drug detention centers in China, Cambodia, Vietnam, and Laos: Health and human rights abuses. Health and Human Rights. 2013; 15(2):124-37.

[28] Ghani MA, Brown S-E, Khan F, Wickersham JA, Lim SH, Dhaliwal SK, et al. An exploratory qualitative assessment of selfreported treatment outcomes and satisfaction among patients accessing an innovative voluntary drug treatment centre in Malaysia. International Journal of Drug Policy. 2015; 26(2):175-82. [DOI:10.1016/j.drugpo.2014.10.002] [PMID] [PMCID]

[29] Eskandarieh S, Jafari F, Yazdani S, Hazrati N, Saberi-Zafarghandi MB. Compulsory maintenance treatment program amongst Iranian injection drug users and its side effects. International Journal of High Risk Behaviors \& Addiction. 2014; 3(4):e21765. [DOI:10.5812/ijhrba.21765] [PMID] [PMCID]

[30] Alam-mehrjerdi Z, Abdollahi M, Higgs P, Dolan K. Drug use treatment and harm reduction programs in Iran: A unique model of health in the most populated Persian Gulf country. Asian Journal of Psychiatry. 2015; 16:78-83. [DOI:10.1016/j.ajp.2015.06.002] 
[31] Iran Alcoholics Anonymous [Internet]. 2018 [Cited 2020 April 11]. Available from: http://aairan.org.

[32] Iran Rigion of Narcotics Anonymous [Internet]. 2018 [Cited 2020 April 11]. Available from: http://na-iran.org.

[33] Mohseni F, Rafaiee R. Results of Activity of Anonymous Alcoholic Association in Iran. Addiction \& health. 2018;10(1):11-6. 
This Page Intentionally Left Blank 